\title{
PATOGENICIDADE DE Alternaria helianthi (HANSF.) E Alternaria zinniae (PAPE) AO GIRASSOL A PARTIR DE SEMENTES ${ }^{1}$
}

\author{
MARIA ELOÍSA SALUSTIANO', JOSÉ DA CRUZMACHADO ${ }^{3}$, JANICE ELAINE PITTIS ${ }^{4}$
}

\begin{abstract}
RESUMO - O objetivo deste trabalho foi avaliar o efeito de Alternaria helianthi e Alternaria zinniae no desempenho de sementes de girassol. Os efeitos de Alternaria helianthi sobre o desenvolvimento inicial do girassol foram observados por meio de inoculação das sementes e plantas com 10 dias de idade. Plantas de girassol inoculadas com suspensão de esporos apresentaram um elevado índice de doença com redução no estande, no peso verde e altura de plantas, comprometendo assim o desempenho inicial da planta. Resultados semelhantes foram obtidos na inoculação de sementes e plantas de girassol com Alternaria zinniae, mantidas em ambiente controlado. $\mathrm{O}$ alto índice da doença induziu a redução do estande, peso verde e altura de plantas.
\end{abstract}

Termos para indexação: Heliantus annuus L., mancha de alternaria, patologia de sementes.

\section{PATHOGENITICITY OF Alternaria helianthi (HANSF.) AND Alternaria zinniae (PAPE) ON} SUNFLOWER SEEDS

\begin{abstract}
The effects of Alternaria helianthi and Alternaria zinniae on the initial development of the sunflower were investigated under controlled conditions from inoculated seeds and 10 day old plants. Inoculated plants with $A$. helianthi spore suspension produced a high index of disease with reduction in stand, fresh weight and plant height. Similar results were obtained in the assay on inoculation of seeds and sunflower plants with Alternaria zinniae. The high index of this disease also induced the reduction of stand, fresh weight and plant height.
\end{abstract}

Index terms: Heliantus annuus L., alternaria leaf spot, seed pathology

\section{INTRODUÇÃO}

A mancha de alternaria, causada pelo fungo Alternaria helianthi (Hansf.) Tubaki e Nishihara, é o principal problema fitossanitário do girassol (Moraes et al., 1983), causando crestamento em todos os estágios de crescimento. Lesões causadas por Alternaria helianthi, desenvolvem-se mais rapidamente em folhas e plantas no estádio de enchimento de grãos e em folhas velhas. A germinação e ramificação dos tubos germinativos aumentam quando, conídios de Alternaria helianthi são misturados ao pólen do capítulo, favorecendo a

${ }^{1}$ Submetido em 20/11/2003. Aceito para publicação em 10/08/2004. Parte da Dissertação de mestrado em Fitotecnia da Universidade Federal de Lavras (UFLA) - MG, desenvolvida com recursos do FINEP, apresentada pelo primeiro autor.

${ }^{2}$ Mestranda do Programa de Pós-Graduação em Fitotecnia, UFLA, 37200- suscetibilidade do girassol no estádio de enchimento dos grãos (Allen et al.1983c). A fase de maturação da cultura torna-se então apropriada ao desenvolvimento da doença quando aliada as condições do ambiente (Allen et al. 1983a). Do ponto de vista epidemiológico $A$. helianthi em baixos níveis nas sementes é capaz de causar sérios danos à cultura em condições favoráveis à doença. De maneira geral, em áreas com cultivo recente de girassol, o crestamento se agrava a partir do segundo cultivo (Allen et al., 1983 b; Jeffrey et al., 1984).

000. E-mail: msalustiano@yahoo.com.br

${ }^{3}$ Eng. Agrônomo Ph.D., Professor Titular do Departamento de Fitopatologia daUFLA.machado@ufla.br

${ }^{4}$ Pesquisadora do Departamento de Fitopatologia da UFLA Cx. Postal 37, 37200-000, Lavras-MG 
As lesões são freqüentes nas folhas, pecíolos, hastes, capítulos e partes florais. (Aquino et al. 1971, Tanaka, 1981 e Moraes et al. 1983). Quando a severidade é crítica, causa pontuações necróticas que coalescem, formando áreas extensas de tecido necrosado, provocando crestamento prematuro da folha, desfolha precoce e morte das plantas (Leite, 1997).

As condições favoráveis à infecção causada por Alternaria helianthi ao girassol são: temperatura alta e umidade elevada durante a estação de crescimento; estas favorecem também a esporulação do fungo. As temperaturas de 25 a $28^{\circ} \mathrm{C}$ favorecem a germinação de conídios de Alternaria helianthi, em presença de umidade na superfície da folha. Nestas circunstâncias ocorre o máximo de infecção num período de 12 horas de alta umidade (Moraes et al., 1983).

Há correlação negativa entre o aumento da intensidade da doença, a produção e a quantidade de óleo produzida. Há redução substancial no valor desses parâmetros devido à atuação da doença. Todos os componentes tais como tamanho de flores, número de sementes por capítulo, sementes produzidas por planta, peso de 1000 sementes, além de produção por parcela e quantidade de óleo, são afetados adversamente. O componente mais afetado é sempre o número de sementes por capítulo, seguido pelo número de sementes por planta (Balasubramanyam \& Kolte, 1980 e Allen et al., 1983d).

Os sintomas causados por $A$. helianthi são semelhantes aos sintomas descritos para $A$. zinniae, outra espécie patogênica ao girasso (MacDonald \& Martens, 1943; Machado, 1980). Esta similaridade de sintomas pode impedir o reconhecimento de uma ou outra espécie em condições de campo, sendo aconselhável identificar o patógeno através de outros meios além da sintomatologia. A A. zinniae, quando inoculada em sementes de girassol resulta em plantas com sintomas típicos àqueles descritos em outros hospedeiros infectados, algumas plântulas apodrecem totalmente e nem mesmo chegam a emergir e outras, após a emergência, exibem lesões nos cotilédones, hipocótilo e tombamento (McDonald \& Martens, 1943).

Desta forma, a utilização de sementes sadias é um dos requisitos de suma importância para assegurar bons rendimentos em qualquer cultivo agrícola. Diante dos poucos estudos realizados em patologia de sementes de girassol no Brasil, o presente trabalho foi proposto com o objetivo de avaliar os efeitos de Altenaria helianthi e Alternaria zinniae sobre o desenvolvimento inicial do girassol em condições controladas, partindo-se da contaminação artificial.

\section{MATERIAL E MÉTODOS}

Os isolados de Alternaria helianthi e Alternaria zinniae usados neste trabalho foram obtidos de sementes de girassol.

Considerando a baixa produção de conídios de $A$. helianthi em meios convencionais, a produção de inóculo foi realizada seguindo o método proposto por Allen et al. (1983e). Inicialmente, foram preparadas placas de petri de $9 \mathrm{~cm}$ de diâmetro contendo $7 \mathrm{~mL}$ de meio composto de extrato de sementes de girassol e $20 \mathrm{~g}$ de sacarose em cada placa. Sobre o meio foram colocados três discos de papel de filtro esterilizados. A seguir discos retirados de colônias desenvolvidas em meio BDA, enriquecido com $100 \mathrm{~g}$ de extrato de semente de girassol, contendo conídios, foram depositados sobre os discos de papel de filtro, de modo que os conídios fossem produzidos sobre a superfície deste substrato. As placas foram incubadas a $28 \pm 1{ }^{\circ} \mathrm{C}$ no escuro durante 15 dias. Ao final deste período, os conídios foram coletados para preparo do inóculo.

A suspensão inicial de conídios foi obtida mergulhandose os discos de papel de filtro em água, após raspagem da superfície dos mesmos com auxílio de pincel. A contagem de conídios, em suspensão, foi realizada através da câmara de Newbauer. Em seguida, ajustou-se as concentrações de inóculo para $10^{5}$ e $2.10^{5}$ esporos $\mathrm{mL}^{-1}$, a testemunha consistiu de água.

$\mathrm{O}$ inóculo de $A$. zinniae foi multiplicado em meio BDA, contido em placas de petri de $9 \mathrm{~cm}$ de diâmetro e incubadas a uma temperatura de $20 \pm 2{ }^{\circ} \mathrm{C}$, sob regime de 12 horas de luz negra alternando com 12 horas de escuro. Após oito dias de incubação, preparou-se a suspensão de conídios. Em cada placa foram adicionados $10 \mathrm{~mL}$ de água destilada e os conídios colocados em suspensão com o auxílio de raspagem com pincel. A padronização da concentração de conídios foi realizada conforme descrito para $A$. helianthi.

Para este estudo com as duas espécies de Alternaria foi usada a cultivar IAC Anhandy que é susceptível aos dois patógenos em condições de campo. Foram comparados dois métodos de inoculação: (1) imersão de sementes em suspensão de conídios e (2) atomização de plantas com suspensão do inóculo. No ensaio de imersão, metade das sementes foi inoculada sem tegumento. Neste caso, os tegumentos eram removidos após um período de 8 horas de imersão das sementes em água.

Uma vez obtidas as sementes com e sem tegumentos, essas foram embebidas nas suspensões de conídios por 30 minutos. Em seguida, estas foram semeadas em vasos 
plásticos de $4 \mathrm{~kg}$ contendo mistura de solo e esterco na proporção $2: 1$, previamente tratada com formalina a $2 \%$. Após a semeadura, os vasos contendo sementes com o inóculo de A. helianthi foram cobertos com saco de polietileno transparente e mantidos em casa de vegetação por 48 horas a uma temperatura média de $28^{\circ} \mathrm{C}$ numa faixa de 19 a $30^{\circ} \mathrm{C}$. Depois de 48 horas a cobertura foi retirada. Os vasos que continham sementes inoculadas com $A$. zinniae também foram cobertos com sacos de polietileno, porém levados para sala de crescimento à temperatura de $20 \pm 2{ }^{\circ} \mathrm{C}$ sob regime alternado de 12 horas de luz branca fluorescente, e 12 horas de escuro. Após 72 horas de incubação retirou-se a cobertura plástica dos vasos, conforme estudos realizados por McDonald \& Martens (1943).

A avaliação dos efeitos nos ensaios de inoculações de sementes foi realizada aos 25 dias da semeadura para $A$. helianthi e 15 dias da semeadura para Alternaria zinniae. Nos ensaios de inoculações de plantas, a avaliação foi realizada aos 10 dias da aplicação do inóculo para A.helianthi e aos 5 dias para A. zinniae.

Foram avaliados nestes ensaios os parâmetros: indice de doença, estande final de plantas (\%), massa verde e massa seco da parte aérea das plantas $(\mathrm{g})$, altura de plantas $(\mathrm{cm})$, nos experimentos referentes a inoculação de sementes

O índice de doença (ID) foi obtido segundo Mckinney (1943). Este índice é calculado com base em escala de notas de infecção, aplicando-se a fórmula:

$$
\begin{aligned}
& \text { ID }=\frac{\sum \text { (f. n.). } 100}{\text { F. N }} \\
& \text { Sendo: } \\
& \text { ID = Índice de doença } \\
& \mathrm{f}=\text { número de plantas em cada nota da escala } \\
& \mathrm{n}=\text { grau de infecção da escala } \\
& \mathrm{F}=\text { número total de plantas inoculadas } \\
& \mathrm{N}=\text { grau máximo de infecção }
\end{aligned}
$$

Para o caso de Alternaria helianthi a escala de notas estabelecida foi a seguinte:

0 - Plantas sem lesões; 1 - Plantas levemente infectadas, lesões pequenas e espaçadas com halos.cloróticos nas folhas; 2 -Plantas moderadamente lesionadas; lesões marrom-escuras com centro acinzentado, algumas vezes com zonas concêntricas nas folhas. 3 - Plantas severamente atacadas, manchas marrom-escuras coalescentes algumas folhas secas, devido à coalescência das lesões, caules quebrados fortemente lesionados. 4 - Plantas mortas.

Para A. zinniae:

0 - Plantas sem lesões; 1 - Plantas com poucas e pequenas lesões foliares, sem crestamento; 2 - Plantas com início de encharcamento no caule e lesões mais severas nas folhas; 3 - Plantas com lesões profundas e coalescidas nas folhas e hastes, algumas plantas mortas.

\section{RESULTADOS E DISCUSSÃO}

\section{Efeito da inoculação de Alternaria helianthi em sementes}

A inoculação de sementes de girassol com A. helianthi apresentou maior índice de doença na concentração mais elevada, $2.10^{5}$ esporos $/ \mathrm{mL}$, com conseqüente redução na altura da planta e no estande final. As concentrações de esporos testadas não causaram efeitos às massas frescas e secas das plantas (Tabela1).

A inoculação de sementes de girassol sem tegumento provocou maior índice de doença e menor estande final, quando comparados às sementes inoculadas com tegumento. Não houve diferença para altura, massa verde e seca de planta entre sementes inoculadas com e sem tegumento (Tabela 2). O índice de doença não diferiu nas duas concentrações testadas dentro de cada inoculação, porém houve maior índice de doença para sementes inoculadas sem tegumento, quando comparadas àquelas com tegumento.

TABELA1. Médias das variáveis avaliadas no ensaio de inoculação de sementes de girassol com e sem tegumento da cultivar IAC Anhandy com Alternaria helianthi.

\begin{tabular}{lccccc}
\hline $\begin{array}{l}\text { Concentração } \\
(\text { Esporos/mL) }\end{array}$ & $\begin{array}{c}\text { Índice de doenças } \\
(\%)\end{array}$ & $\begin{array}{c}\text { Estande final } \\
(\%)\end{array}$ & $\begin{array}{c}\text { Altura de planta } \\
(\mathrm{cm})\end{array}$ & $\begin{array}{c}\text { Peso verde } \\
(\mathrm{g})\end{array}$ & $\begin{array}{c}\text { Peso seco } \\
(\mathrm{g})\end{array}$ \\
\hline 0 & $4,06 \mathrm{c}$ & $10,00 \mathrm{a}$ & $32,92 \mathrm{a}$ & $75,50 \mathrm{a}$ & $4,72 \mathrm{a}$ \\
$10^{5}$ & $45,29 \mathrm{~b}$ & $9,60 \mathrm{a}$ & $28,66 \mathrm{~b}$ & $63,30 \mathrm{a}$ & $4,59 \mathrm{a}$ \\
$2,10^{5}$ & $47,24 \mathrm{a}$ & $9,40 \mathrm{~b}$ & $27,53 \mathrm{~b}$ & $57,63 \mathrm{a}$ & $4,37 \mathrm{a}$ \\
\hline $\mathrm{CV}$ & 6,24 & 3,55 & 10,53 & 22,01 & 26,56 \\
\hline
\end{tabular}

Médias seguidas de mesma letra nas colunas não diferem entre si, pelo teste de Tukey $(\mathrm{P}<0,05)$. 
TABELA 2. Médias das variáveis avaliadas no ensaio de inoculação de sementes de girassol com e sem tegumento da cultivar IAC Anhandy com Alternaria helianthi nas diferentes concentrações.

\begin{tabular}{lccccc}
\hline $\begin{array}{l}\text { Concentração } \\
(\text { Esporos/mL) }\end{array}$ & $\begin{array}{c}\text { Índice de doenças } \\
(\%)\end{array}$ & $\begin{array}{c}\text { Estande final } \\
(\%)\end{array}$ & $\begin{array}{c}\text { Altura de } \\
\text { planta }(\mathrm{cm})\end{array}$ & $\begin{array}{c}\text { Peso verde } \\
(\mathrm{g})\end{array}$ & $\begin{array}{c}\text { Peso seco } \\
(\mathrm{g})\end{array}$ \\
\hline Com tegumento & $25,61 \mathrm{~b}$ & $9,82 \mathrm{a}$ & $29,44 \mathrm{a}$ & $67,36 \mathrm{a}$ & $4,22 \mathrm{a}$ \\
Sem tegumento & $37,77 \mathrm{a}$ & $9,51 \mathrm{~b}$ & $29,97 \mathrm{a}$ & $63,59 \mathrm{a}$ & $4,89 \mathrm{a}$ \\
\hline
\end{tabular}

Médias seguidas de mesma letra nas colunas não diferem entre si, pelo teste de Tukey $(\mathrm{P}<0,05)$.

Os resultados obtidos nas condições deste ensaio revelam que, quanto maior a concentração de inóculo de Alternaria helianthi maior será o índice de doença e menor o número de plantas sobreviventes. Sementes inoculadas sem tegumento resultam em plantas com maior índice de doença (Tabela 3). Prasad \& Kulshrestha (1996) detectaram A. helianthi em amostras de sementes naturalmente infectadas, o fungo foi encontrado no pericarpo, endocarpo e embrião. Sementes infectadas quando semeadas originaram plântulas com lesões.

Efeito da inoculação de Alternaria helianthi em plantas

A inoculação de $A$. helianthi em plantas de girassol proporcionou uma elevação no índice de doença nas duas concentrações utilizadas, não havendo, entretanto, diferenças significativas entre essas concentrações de inóculo. À medida que se aumentou a concentração de esporos, houve uma redução do estande final e da massa verde de plantas. Embora as diferenças entre valores da testemunha e a concentração mais baixa para estande final, massa verde e seco não tenham

TABELA3. Efeito da concentração de esporos de $A$. helianthi em sementes de IAC Anhandy inoculadas com e sem tegumento.

\begin{tabular}{lcc}
\hline Concentração & \multicolumn{2}{c}{ ìndice de doença } \\
\cline { 2 - 3 }$($ Esporos $/ \mathrm{mL})$ & Com tegumento & Sem tegumento \\
\hline 0 & $4,05 \mathrm{~b} \mathrm{~A}$ & $4,05 \mathrm{~b} \mathrm{~A}$ \\
$10^{5}$ & $36,17 \mathrm{a} \mathrm{B}$ & $54,41 \mathrm{a} \mathrm{A}$ \\
$2,10^{5}$ & $39,62 \mathrm{a} \mathrm{B}$ & $54,86 \mathrm{a} \mathrm{A}$ \\
\hline
\end{tabular}

Médias seguidas de mesma letra, minúscula na coluna e maiúscula na linha não diferem entre si, pelo teste de Tukey $(\mathrm{P}<0,05)$. sido estatisticamente significativas.

Em relação ao peso seco não houve efeito significativo de nenhuma das concentrações de esporo (Tabela 4). Vale salientar que a cultivar IAC Anhandy, tem-se apresentado como menos susceptível a $A$ helianthi em algumas regiões conforme relatos de Godoy \& Gimenes (1985b).

Efeito da inoculação de Alternaria zinneae em sementes

O efeito significativo da inoculação de plantas da cultivar IAC Anhandy com A. zinniae, de acordo com as análises estatísticas realizadas, foi observado apenas para as interações concentração x índice de doença (Tabela 5). Não houve diferença estatística entre os valores de índice de doença correspondente às concentrações $10^{5}$ e $2.10^{5}$ esporos $\mathrm{mL}^{-1}$. Porém, as duas concentrações apresentaram altos índices de infecção, quando comparados com a testemunha. De forma semelhante, mas em proporções menores, o estande final e massa verde de plantas foram significativamente reduzidos, em função da inoculação, utilizando-se duas concentrações de esporos. Por outro lado, para altura e massa seca de plantas, a inoculação com $A$. zinniae não causou diferenças estatísticas entre os valores avaliados, o que evidencia que para essas variáveis, o efeito de $A$. zinniae é bem distinto de A. helianthi (Tabela 5).

Não houve diferença entre valores correspondentes à inoculação de sementes com e sem tegumento para nenhuma das variáveis consideradas. Ao contrário do que ocorreu com A. helianthi, observa-se que o efeito de A.zinniae não foi limitado pelo tegumento (Tabela 6). Embora não tenha havido

TABELA 4. Médias das variáveis avaliadas no ensaio de inoculação de plantas de girassol, cultivar IAC Anhandy com Alternaria helianthi.

\begin{tabular}{lcccc}
\hline $\begin{array}{l}\text { Concentração } \\
\text { (Esporos/mL) }\end{array}$ & $\begin{array}{c}\text { Índice de doenças } \\
(\%)\end{array}$ & $\begin{array}{c}\text { Estande final } \\
(\%)\end{array}$ & $\begin{array}{c}\text { Altura de planta } \\
(\mathrm{cm})\end{array}$ & $\begin{array}{c}\text { Massa seca } \\
(\mathrm{g})\end{array}$ \\
\hline 0 & $4,06 \mathrm{~b}$ & $10,00 \mathrm{a}$ & $40,02 \mathrm{a}$ & $3,00 \mathrm{a}$ \\
$10^{5}$ & $44,38 \mathrm{a}$ & $9,47 \mathrm{a}$ & $33,40 \mathrm{a}$ & $2,95 \mathrm{a}$ \\
$2,10^{5}$ & $51,12 \mathrm{a}$ & $8,46 \mathrm{~b}$ & $21,69 \mathrm{~b}$ & $2,10 \mathrm{a}$ \\
\hline $\mathrm{CV}$ & 17,24 & 7,62 & 39,53 & 37,48 \\
\hline
\end{tabular}

Médias seguidas de mesma letra nas colunas não diferem entre si, pelo teste de Tukey $(\mathrm{P}<0,05)$. 
TABELA 5. Médias das variáveis avaliadas no ensaio de inoculação de sementes de girassol, cultivar IAC Anhandy com Alternaria zinniae.

\begin{tabular}{lccccc}
\hline $\begin{array}{l}\text { Concentração } \\
(\text { Esporos/mL) }\end{array}$ & $\begin{array}{c}\text { Índice de doenças } \\
(\%)\end{array}$ & $\begin{array}{c}\text { Estande final } \\
(\%)\end{array}$ & $\begin{array}{c}\text { Altura de planta } \\
(\mathrm{cm})\end{array}$ & $\begin{array}{c}\text { Peso verde } \\
(\mathrm{g})\end{array}$ & $\begin{array}{c}\text { Peso seco } \\
(\mathrm{g})\end{array}$ \\
\hline 0 & $4,06 \mathrm{~b}$ & $10,00 \mathrm{a}$ & $15,69 \mathrm{a}$ & $6,75 \mathrm{a}$ & $0,52 \mathrm{a}$ \\
$10^{5}$ & $52,52 \mathrm{a}$ & $8,83 \mathrm{c}$ & $14,53 \mathrm{a}$ & $5,29 \mathrm{~b}$ & $0,48 \mathrm{a}$ \\
$2,10^{5}$ & $53,75 \mathrm{a}$ & $9,39 \mathrm{~b}$ & $15,15 \mathrm{a}$ & $4,79 \mathrm{~b}$ & $0,47 \mathrm{a}$ \\
\hline $\mathrm{CV}$ & 14,97 & 3,78 & 8,80 & 14,43 & 10,65 \\
\hline
\end{tabular}

Médias seguidas de mesma letra nas colunas não diferem entre si, pelo teste de Tukey $(\mathrm{P}<0,05)$.

TABELA 6. Médias das variáveis avaliadas no ensaio de inoculação de sementes de girassol, com e sem tegumento, cultivar IAC Anhandy com Alternaria zinneae.

\begin{tabular}{lccccc}
\hline $\begin{array}{l}\text { Concentração } \\
\text { (Esporos/mL) }\end{array}$ & $\begin{array}{c}\text { Índice de } \\
\text { doenças }(\%)\end{array}$ & $\begin{array}{c}\text { Estande final } \\
(\%)\end{array}$ & $\begin{array}{c}\text { Altura de planta } \\
(\mathrm{cm})\end{array}$ & $\begin{array}{c}\text { Peso verde } \\
(\mathrm{g})\end{array}$ & $\begin{array}{c}\text { Peso seco } \\
(\mathrm{g})\end{array}$ \\
\hline Com tegumento & $37,38 \mathrm{~b}$ & $9,39 \mathrm{a}$ & $14,82 \mathrm{a}$ & $5,70 \mathrm{a}$ & $0,49 \mathrm{a}$ \\
Sem tegumento & $36,16 \mathrm{a}$ & $9,42 \mathrm{~b}$ & $14,44 \mathrm{a}$ & $5,47 \mathrm{a}$ & $0,48 \mathrm{a}$ \\
\hline
\end{tabular}

Médias seguidas de mesma letra nas colunas não diferem entre si, pelo teste de Tukey $(\mathrm{P}<0,05)$.

diferença entre os valores correspondentes à inoculação com e sem tegumento (Tabela 7), para a inoculação com tegumento houve uma redução no estande na concentração de $10^{5}$ esporos $/ \mathrm{mL}$. Isto ocorreu talvez pelo fato desta concentração de esporos já ser suficiente para causar um alto índice de doença e qualquer concentração acima dela pode levar a redução da infecção, ao invés de uma elevação da mesma. Houve redução do estande para sementes inoculadas sem tegumento. A $A$. zinniae inoculada em sementes de girassol causou um alto índice de doença, além de redução do estande final.

Efeito da inoculação de Alternaria zinniae em plantas

A. zinniae foi capaz de causar infecções a cultivar IAC Anhandy, bem como reduzir o estande final e massa verde das plantas, em ambas as concentrações de inóculo. $\mathrm{O}$ aumento de concentração do inóculo provocou um efeito mais acentuado em relação ao índice de doença e peso verde. A massa seca das plantas não foi afetada pela inoculação do patógeno em questão (Tabela 8). Estes resultados revelam que a cultivar IAC Anhandy é sensível a $A$. zinniae, apresentando um alto índice de doença e uma considerável redução da parte aérea comparada com $A$. helianthi.

TABELA 7. Efeito da concentração de esporos de $A$. zinneae sobre sementes de girassol, cultivar IAC Anhandy inoculadas com e sem tegumento.

\begin{tabular}{lrr}
\hline Concentração & \multicolumn{2}{c}{ Índice de doença } \\
\cline { 2 - 3 }$($ Esporos $/ \mathrm{mL})$ & Com tegumento & Sem tegumento \\
\hline 0 & $10,00 \mathrm{a} \mathrm{A}$ & $10,00 \mathrm{a} \mathrm{A}$ \\
$10^{5}$ & $8,60 \mathrm{~b} \mathrm{~B}$ & $9,06 \mathrm{~b} \mathrm{~A}$ \\
$2,10^{5}$ & $9,59 \mathrm{a} \mathrm{B}$ & $9,19 \mathrm{~b} \mathrm{~A}$ \\
\hline
\end{tabular}

Médias seguidas de mesma, letra minúscula na coluna e maiúsculas nas linha não diferem entre si, pelo teste de Tukey $(\mathrm{P}<0,05)$.

TABELA 8. Médias das variáveis avaliadas no ensaio de inoculação de plantas de girassol, cultivar IAC Anhandy com Alternaria zinniae.

\begin{tabular}{lcccc}
\hline Concentração (Esporos $/ \mathrm{mL})$ & Índice de doenças (\%) & Estande final (\%) & Altura de planta $(\mathrm{cm})$ & Peso seco $(\mathrm{g})$ \\
\hline 0 & $4,06 \mathrm{c}$ & $10,00 \mathrm{a}$ & $40,02 \mathrm{a}$ & $3,00 \mathrm{a}$ \\
$10^{5}$ & $57,36 \mathrm{~b}$ & $9,47 \mathrm{~b}$ & $33,40 \mathrm{a}$ & $2,95 \mathrm{a}$ \\
$2,10^{5}$ & $63,88 \mathrm{a}$ & $8,46 \mathrm{~b}$ & $21,69 \mathrm{~b}$ & $2,10 \mathrm{a}$ \\
\hline
\end{tabular}

Médias seguidas de mesma letra nas colunas não diferem entre si, pelo teste de Tukey $(\mathrm{P}<0,05)$. 


\section{CONCLUSÕES}

A presença de Alternaria helianthi como contaminante de sementes de girassol é capaz de causar alto índice de doença, redução do estande, massa verde e altura de plantas. Com relação a Alternaria zinniae, altas concentrações de esporos causam elevado índice de doença e redução do estande na fase inicial do desenvolvimento do girassol. As sementes sem tegumento sofrem mais efeitos da contaminação com Alternaria do que as sementes com tegumento.

\section{REFERÊNCIAS}

ALLEN, S.J.; BROWN, J.F.; KOCHMAN, J.K. Effects of leaf age, host growth stage, leaf injury, and pollen on the infection of sunflower by Alternaria helianthi. Phytopathology, St. Paul, v.73, n.6, p.896-898, $1983 \mathrm{a}$.

ALLEN, S.J.; BROWN, J.F.; KOCHMAN, J.K. Effects of temperature, dew period, and length on the growth and development of Alternaria helianthi. Phytopathology, St. Paul, v.73, n.6, p.893-896, 1983 b.

ALLEN, S.J.; BROWN, J.F.; KOCHMAN, J.K. The infection process sporulation and survival of Alternaria helianthi on sunflower. Annals of Applied Biology, London, v.102, n.3, p.413419, $1983 \mathrm{c}$.

ALLEN, S.J.; BROWN, J.F.; KOCHMAN, J.K. Losses in sunflower yield caused by Alternaria helianthi in Southern Queensland. Australian Journal of Agriculture and Animal Husbandry, Victoria, v.21, n.108, p.98-100, 1983d.

ALLEN, S.J.; BROWN, J.F.; KOCHMAN, J.K. Production for inoculum and field assement of Alternaria helianthi on sunflower. Plant Disease, Washington, v.67, n.6, p.665-668, 1983e.
AQUINO, M.L.N.; BEZERRA, J.L.; LIRA, M.A. Ocorrência do crestamento do girassol (Helianthus annuus L.) em Pernambuco. Revista de Agricultura, Piracicaba, v. 46, n.4, p.151-156, 1971.

BALASUBRAHMANYAM, N.; DOLTE, S.J. Effect of different intensities of Alternaria blight on yield and oil content of sunflower. Journal of Agricultural Science, Cambridge, v. 94, n.3, p.749-751, 1980.

GODOY, J.R.; GIMENES, F.N. Epidemiologia da mancha de Alternaria helianthi em girassol (Helianthus annuus L.) Summa Phytopathologica, Piracicaba, v.11, n.1/2, p.1, 1985.

JEFFREY, K.K.; LIPPS, P.E.; HERR, L.J. Effects of isolate virulence, plant age and crop residues on seedling blight of sunflower caused by Alternaria helianthi. Phytopathology, St. Paul, v.74, n.9, p.107110, 1984.

LEITE, R.M.V.B.C. Doenças do girassol. Londrina: EMBRAPA/ CNPSo, 1997. 68 p. Circular Técnica, 19.

McDONALD, W.C.; MARTENS, J.W. Leaf and stem spot of sunflowers caused by Alternaria zinniae. Phytopathology, St. Paul, v.33, n.3, p.372-381, 1943.

MORAES, S.A; UNGARO, M.R.G.; MENDES, B.M.J. Alternaria helianthi agente causal de doença em girassol. Campinas: Fundação Cargill, 1983. 20p.

MACHADO, J.C. Studies on some seed-borne diseases of zinnia, African marigold and soybean. 1980. 187f. Tese (Ph.D)- University of Manchester, Manchester, 1980.

MCKINNEY, H.H. Influence of soil temperature and moisture on infection of wheat seedlings by Helminthosporium sativum. Journal of Agricultural Research, Washington, v. 26, n. 5, p.195219, 1923.

PRASAD, R.D.; KULSHRESTHA, D.D. Seedborne nature of Alternaria in sunflower, its detection and location in seed. Seed Research, Alexandria, v.24, n.2, p.141-144, 1996.

TANAKA, M.A. Doenças do girassol. Informe Agropecuário, Belo Horizonte, v.7, n.82, p.84-86, 1981. 